\title{
A Relação Público-Privada na Oferta da Educação Infantil em Porto Alegre
}

\author{
Vera Maria Vidal Peroni' \\ Maria Otilia Kroeff Susin" \\ Monique Montano"
}

'Universidade Federal do Rio Grande do Sul (UFRGS), Porto Alegre/RS - Brasil

"Secretaria Municipal de Educação (SMED), Porto Alegre/RS - Brasil

RESUMO - A Relação Público-Privada na Oferta da Educação Infantil em Porto Alegre. O artigo apresenta a pesquisa sobre a parceria do poder público com instituições da sociedade civil para a oferta de educação infantil, no município de Porto Alegre, capital do Rio Grande do Sul, no período de 2017 a 2019. O referencial teórico-metodológico consultado parte da materialização do Estado, em um processo de correlação de forças, construídas historicamente por sujeitos que demandam políticas públicas. Constatouse o incremento do setor privado na oferta e execução da política municipal de educação infantil, com implicações para a democratização do acesso e do atendimento das crianças. Assim, o direito à educação infantil não se concretiza plenamente, fortalecendo as desigualdades em uma sociedade de classes.

Palavras-chave: Estado. Parceria Público-Privada. Educação Infantil.

ABSTRACT - The Public-Private Relationship in the Offer of Early Childhood Education in Porto Alegre. The current paper presents a research about the partnership between the public sector and civil society institutions for the provision of early childhood programs in the city of Porto Alegre/Rio Grande do Sul state, during the years of 2017 and 2019. The theoretical and methodological approach was based on the materialization of the State, in a process of correlation between the forces that are historically built for individuals that require public policies. Due to this research, we have confirmed the growth of the private sector in the offer and execution of the city policies for early childhood education, with implication for the democratization of access and child support. Thus, the right to early childhood education is not entirely tangible, reinforcing the disparities in a class society.

Keywords: State. Public/Private Partnership. Child Education.

Educação \& Realidade, Porto Alegre, v. 46, n. 3, e105676, 2021. 
A Relação Público-Privada na Oferta da Educação Infantil em Porto Alegre

\section{Introdução}

O presente texto tem por objetivo instigar o debate acerca da oferta da educação infantil conveniada, legalmente transformada em parceria no ano de 2017, sendo uma das formas de materialização da privatização do público, uma realidade histórica, porém muito intensificada neste período particular do capitalismo. Apresentaremos a discussão através de um exemplo específico, uma situação da cidade de Porto Alegre, de modo a dar concretude ao debate e apresentar elementos teóricos e analíticos acerca do tema.

A concepção teórica aqui apresentada dialoga com autores como Montaño (2002), Wood (2003), Vieira (2004) e Peroni (2018) e analisa a reconfiguração do Estado e as políticas sociais, como materialização de direitos sociais.

A história da educação infantil comunitária em Porto Alegre é estudada a partir do movimento do real, presente nas construções dos sujeitos sociais e das comunidades, na organização e no suprimento de demandas não atendidas. A parceria entre o Estado e o movimento social comunitário é repleta de contradições e as pesquisas que embasam este artigo têm, portanto, o desafio de analisá-las.

O texto está ancorado em um histórico de pesquisas sobre a materialização da privatização do público na educação básica ${ }^{1}$, com implicações para a democratização da educação. Partimos do pressuposto teórico construído ao longo das pesquisas, de que a relação entre o público e o privado na educação não se trata apenas de propriedade, mas de projetos societários em disputa, pois tanto no Estado, quanto na sociedade civil existem forças sociais que, pelo importante papel da educação neste processo, defendem projetos com interesses vinculados ao mercado e/ou ao neoconservadorismo, com profundas implicações para a construção de uma sociedade democrática. Entendemos aqui Democracia como a "[...] materialização de direitos em políticas coletivamente construídas na autocrítica da prática social” (Peroni, 2013b).

Para Rikowski (2017), existem duas formas básicas de privatização: a primeira é a privatização clássica ou direta que envolve a venda de ativos públicos diretamente para alguma combinação de empresas, grupos de investidores e investidores individuais e a segunda não envolve a propriedade, mas o controle "a tomada de controle sobre a educação por parte das empresas”, (p. 400), em oposição à sua privatização direta. Nesse sentido, e com base nas pesquisas ${ }^{2}$ que realizamos sobre o tema (Peroni; Adrião, 2007; Adrião; Peroni, 2011; Peroni, 2013b; 2015; 2018), verificamos que os processos de privatização do público podem ocorrer via execução e direção, em que o setor privado atua diretamente na oferta da educação, ou quando a atuação do privado ocorre na direção das políticas públicas ou das escolas, sendo que a propriedade permanece pública. Assim, a relação público-privada tem como concepção, não apenas a propriedade, mas os projetos societários em disputa em uma perspectiva de classe. No caso deste artigo, apresentamos a privatização via execução, que ocorre quando o poder público repas- 
sa suas responsabilidades como executor de direitos para instituições da sociedade civil, com ou sem fins lucrativos, para ofertar educação infantil.

As fronteiras entre o público e o privado têm-se modificado no contexto atual de crise do capitalismo e suas estratégias de superação: neoliberalismo, globalização, reestruturação produtiva, terceira via e neoconservadorismo, redefinem o papel do Estado, principalmente para com as políticas sociais. O neoliberalismo afirma que o poder público gastou em demasia com políticas sociais, gerando uma crise. Assim, o Estado não deve mais ser o executor de políticas sociais universais, repassando para o setor privado a execução e direção. Perde-se a concepção de direito, que é substituída por serviços, por meio de ações focalizadas e não mais universais (Abdala; Puello-Socarrás, 2019). É o caso da parceria para oferta da Educação Infantil em Porto Alegre, abordada neste texto.

Este artigo contém, além da introdução, três seções e considerações finais. Na Introdução, apresentamos o referencial teórico-metodológico e os conceitos que embasaram a pesquisa. Na primeira seção, abordamos a parceria da Educação Infantil em Porto Alegre, desde seus primórdios, com dados de matrículas, em uma série histórica, e as análises que dialogam também com o aparato legal e normativo relacionado à temática. A segunda seção abrange a Educação Infantil e as análises em relação ao Plano Nacional de Educação, ao Plano Municipal de Educação de Porto Alegre e à Lei do Fundeb ${ }^{3}$ (2007). Na terceira seção consta nossa avaliação em relação às parcerias e ao papel do Estado. Nas considerações finais encerramos com uma síntese da análise decorrente da pesquisa e nosso posicionamento.

\section{As Parcerias entre o Público e o Privado na Educação Infantil em Porto Alegre}

A educação infantil comunitária conveniada, em Porto Alegre, materializa-se na parceria entre o poder público municipal, por meio da Secretaria Municipal de Educação (SMED), e organizações da sociedade civil sem fins lucrativos. Teve início em 1990, mediante convênio que se manteve até 2016. A partir de 2017, a relação com a sociedade civil passou a ser regulada pelo novo Marco Regulatório das Parcerias.

O convênio era definido, até 2016, por intermédio do Orçamento Participativo (OP), espaço de decisão com participação popular em reuniões preparatórias, assembleias regionais e temáticas e assembleia municipal, no qual eram definidas as prioridades de investimentos para o município.

Em 31 de julho de 2014 foi promulgada a Lei Federal no 13.019 (Brasil, 2014b), novo Marco Regulatório que instituiu normas gerais para as parcerias entre a administração pública e a sociedade civil. Os convênios, desde então, ficaram restritos "entre entes federados ou pessoas jurídicas a eles vinculadas” (Brasil, 2014b, n. p.) e as instituições pri- 
A Relação Público-Privada na Oferta da Educação Infantil em Porto Alegre

vadas que atuam de forma complementar ao Sistema Único de Saúde (SUS). A vigência do Marco Regulatório para os municípios deu-se a partir de janeiro de 2017. No município de Porto Alegre, o Decreto $\mathrm{n}^{\mathrm{o}}$ 19.775, de 27 de junho de 2017, estabeleceu regras para a aplicação da Lei Federal no 13.019. Com tais resoluções, as parcerias entre a Administração Pública e as entidades privadas sem fins lucrativos passaram a ser celebradas pelo Termo de Colaboração ou pelo Termo de Fomento, e não mais pelo Termo de Convênio.

Em Porto Alegre, o processo de repasse da responsabilidade da oferta da educação infantil para o setor privado, como política pública, fica evidente nos números apresentados nas tabelas a seguir. As Tabelas 1 e 2 evidenciam a ampliação da oferta de vagas, por meio dos espaços conveniados de 1997 até 2012, sendo que, em 2012, observa-se significativo aumento das matrículas conveniadas em detrimento das ofertadas nas instituições públicas. Até 2012, segundo os dados obtidos no Boletim Informativo da SMED, do Setor de Pesquisas e Informações Educacionais (PIE), havia 209 estabelecimentos conveniados.

Tabela 1 - Matrículas da Educação Infantil em Porto Alegre (1993 a 2002)

\begin{tabular}{ccccccccccc}
\hline Redes & 1993 & 1994 & 1995 & 1996 & 1997 & 1998 & 1999 & 2000 & 2001 & 2002 \\
\hline $\begin{array}{c}\text { Municipal } \\
\text { Creches }\end{array}$ & - & - & - & - & 5.852 & 5.558 & $4.987^{(1)}$ & $4.849^{(2)}$ & 5.065 & 5.304 \\
$\begin{array}{c}\text { Comunitá- } \\
\text { rias }\end{array}$ & 2.000 & 3.186 & 4.113 & 5.125 & 5.865 & 6.521 & 7.156 & 7.675 & 8.117 & 8.350 \\
Total & 2.000 & $\mathbf{3 . 1 8 6}$ & $\mathbf{4 . 1 1 3}$ & $\mathbf{5 . 1 2 5}$ & $\mathbf{1 1 . 7 1 7}$ & $\mathbf{1 2 . 0 7 9}$ & $\mathbf{1 2 . 1 4 3}$ & $\mathbf{1 2 . 5 2 4}$ & $\mathbf{1 3 . 1 8 2}$ & $\mathbf{1 3 . 6 5 4}$ \\
\hline
\end{tabular}

Fonte: MEC/INEP - Censo Escolar 2004 a 2012. EPED/ASSEPLA/SMED 2000/2010 Boletim Informativo SMED. Notas: (1) (2) Com a implantação dos Ciclos de Formação, as turmas de Jardim B das Escolas de Ensino Fundamental foram incorporadas no $1^{\circ}$ ano do $1^{\circ}$ Ciclo do Ensino Fundamental.

Tabela 2-Matrículas da Educação Infantil em Porto Alegre (2003 a 2012)

\begin{tabular}{|c|c|c|c|c|c|c|c|c|c|c|}
\hline Redes & 2003 & 2004 & 2005 & 2006 & 2007 & 2008 & 2009 & 2010 & 2011 & 2012 \\
\hline Municipal & 5.415 & 5.558 & 5.699 & 5.399 & 5.262 & 5.080 & 5.254 & 5.525 & 5.557 & 5.801 \\
\hline $\begin{array}{c}\text { Creches } \\
\text { Comunitá- } \\
\text { rias }\end{array}$ & 8.399 & 8.915 & 9.277 & 8.961 & 9.255 & 11.162 & 12.884 & 13.302 & 13.574 & 15.096 \\
\hline Total & 13.814 & 14.473 & 14.976 & 14.360 & 14.517 & 16.242 & 18.138 & 18.827 & 19.131 & 20.897 \\
\hline
\end{tabular}

Enquanto na Rede Municipal, em 2012 o número de matrículas na educação infantil era de 5.801 , as creches comunitárias conveniadas ofertavam 15.096, ou seja, $160 \%$ a mais de matrículas. No entanto, em que pese o crescimento da rede pública, as matrículas ofertadas pelos convênios eram significativamente mais numerosas. 
Considerando que o Termo de Colaboração foi celebrado no município em 2017, é fundamental apresentar os dados do ano de 2016, quando as instituições ainda operavam sob o Termo de Convênio. Em 2017, a Secretaria Municipal de Educação assinou Termo de Colaboração com 226 instituições. Os Quadros 1 e 2, abaixo, evidenciam essa realidade.

Quadro 1 - Matrículas da Educação Infantil em Porto Alegre (2016 a 2017)

\begin{tabular}{|c|c|c|c|c|c|c|c|c|}
\hline Ano & \multicolumn{3}{|c|}{ 2016* $^{*}$} & \multicolumn{3}{c|}{ 2017** } \\
\hline Rede & \multicolumn{2}{|c|}{ Pública } & \multicolumn{2}{c|}{ Parceira } & \multicolumn{2}{c|}{ Pública } & \multicolumn{2}{c|}{ Parceira } \\
\hline Faixa & Creche & $\begin{array}{c}\text { Pré- } \\
\text { escola }\end{array}$ & Creche & $\begin{array}{c}\text { Pré- } \\
\text { escola }\end{array}$ & Creche & $\begin{array}{c}\text { Pré- } \\
\text { escola }\end{array}$ & Creche & $\begin{array}{c}\text { Pré- } \\
\text { escola }\end{array}$ \\
\hline Matrículas & 2.482 & 3.872 & 6.474 & 5.554 & 2.198 & 5.449 & 6.879 & 5.667 \\
\hline $\begin{array}{c}\text { Total matr. } \\
\text { por Rede }\end{array}$ & \multicolumn{3}{|c|}{6.354} & \multicolumn{2}{|c|}{12.028} & & 7.647 & 12.546 \\
\hline $\begin{array}{c}\text { Total de } \\
\text { matrículas }\end{array}$ & \multicolumn{3}{|c|}{18.382} & \multicolumn{3}{c|}{20.193} \\
\hline
\end{tabular}

Fonte: Elaborado pelas autoras com base nas Portarias Interministeriais: *n. 06, de 21 de julho de 2016 e **n. 8, de 29 de novembro de 2017.

Quadro 2-Matrículas da Educação Infantil em Porto Alegre (2018 a 2019)

\begin{tabular}{|c|c|c|c|c|c|c|c|c|}
\hline Ano & \multicolumn{3}{|c|}{ 2018* $^{*}$} & \multicolumn{3}{c|}{ 2019** } \\
\hline Rede & \multicolumn{2}{|c|}{ Pública } & \multicolumn{2}{c|}{ Parceira } & \multicolumn{2}{c|}{ Pública } & \multicolumn{2}{c|}{ Parceira } \\
\hline Faixa & Creche & $\begin{array}{c}\text { Pré- } \\
\text { escola }\end{array}$ & Creche & $\begin{array}{c}\text { Pré- } \\
\text { escola }\end{array}$ & Creche & $\begin{array}{c}\text { Pré- } \\
\text { escola }\end{array}$ & Creche & $\begin{array}{c}\text { Pré- } \\
\text { escola }\end{array}$ \\
\hline Matrículas & 2.223 & 5.768 & 7.773 & 6.901 & 2.230 & 5.745 & 7.938 & 7.626 \\
\hline $\begin{array}{c}\text { Total matr. } \\
\text { por Rede }\end{array}$ & \multicolumn{2}{|c|}{7.991} & \multicolumn{2}{|c|}{14.674} & \multicolumn{2}{c|}{7.975} & 15.564 \\
\hline $\begin{array}{c}\text { Total de } \\
\text { matrículas }\end{array}$ & \multicolumn{3}{|c|}{22.665} & \multicolumn{3}{c|}{23.539} \\
\hline
\end{tabular}

Fonte: Elaborado pelas autoras com base nas Portarias Interministeriais: ${ }^{*} \mathrm{n} .06$, de 26 de dezembro de $2018 \mathrm{e}^{* *} \mathrm{n} .07$, de 28 de dezembro de 2018.

A oferta da educação infantil, no município de Porto Alegre, é regulamentada pelo Conselho Municipal de Educação (CME), e, para que essas instituições fizessem parte do financiamento público da educação, elas deveriam ser credenciadas e autorizadas pelo CME. No entanto, o inciso IV, do $\$ 2^{\circ}$, do artigo $8^{\circ}$ da Lei ${ }^{\circ} 11.494$, de 20 de junho de 2007 (Brasil, 2007), que cria o Fundo de Manutenção e Desenvolvimento da Educação Básica e de Valorização dos Profissionais da Educação (Fundeb), afirma que, para essas instituições terem suas matrículas computadas, no respectivo fundo, deverão "obrigatória e cumulativamente [...] IV - atender a padrões mínimos de qualidade definidos pelo órgão normativo do sistema de ensino, inclusive, obrigatoriamente, ter aprovado seus projetos pedagógicos" (Brasil, 2007). A mesma Lei consagra, nos $\$ \S 1^{\circ}$ e $3^{\circ}$ do artigo citado que,

[...] para efeito da distribuição dos recursos previstos no inciso II do caput do art. 60 do ADCT, em relação às instituições comunitárias, confessionais ou filantrópicas 
A Relação Público-Privada na Oferta da Educação Infantil em Porto Alegre

sem fins lucrativos e conveniadas com o poder público, o cômputo das matrículas efetivadas: I - na educação infantil oferecida em creches para crianças de até 3 (três) anos; [e] § 3o Será admitido, até 31 de dezembro de 2016 , o cômputo das matrículas das pré-escolas, comunitárias, confessionais ou filantrópicas, sem fins lucrativos, conveniadas com o poder público e que atendam a crianças de 4 (quatro) a 5 (cinco) anos, observadas as condições previstas nos incisos I a V do $\S 20$, efetivadas, conforme o censo escolar mais atualizado, realizado pelo Instituto Nacional de Estudos e Pesquisas Educacionais Anísio Teixeira - INEP (Brasil, 2007).

O Conselho Nacional de Educação, quando normatiza a educação infantil brasileira, o faz por meio de suas diretrizes, que devem ser observadas por todas as instituições que oferecem educação infantil. Nesse sentido, há que se destacar o Parecer CNE/CEB no 20, de 11 de novembro de 2009 (Brasil, 2009), ainda em vigência, que revisa as diretrizes nacionais para a educação infantil e enfatiza as questões pedagógicas dessa etapa da educação básica. Dentro do amplo conteúdo trabalhado nesse documento, destaca-se a função sociopolítica dessa etapa da educação, que tem por base a proposta pedagógica e curricular das instituições que cuidam e educam crianças pequenas. Destaque há que ser feito, ainda, para a responsabilidade educativa desse trabalho, cuja finalidade é criar situações para que a criança possa desenvolverse e apropriar-se de conhecimentos básicos que levem em conta, "O paradigma do desenvolvimento integral da criança a ser necessariamente compartilhado com a família [...]" (Brasil, 2009).

O mesmo documento faz importante reflexão sobre o direito das famílias e das crianças à educação infantil, direito este que "[...] se inscreve no projeto de sociedade democrática [...]”, estabelecido pela Constituição Federal de 1988 (Brasil, 1988), e a preocupante desigualdade no acesso e na qualidade da educação ofertada às crianças, configurandose "[...] em violações de direitos constitucionais das mesmas", por se caracterizarem como espaços que, "[...] ao invés de promover a equidade, alimentam e reforçam as desigualdades socioeconômicas, étnicoraciais e regionais" (Brasil, 2009).

Susin (2009) afirma que as desigualdades na qualidade da educação infantil também tomam corpo pela naturalização do possível, representada por condições inadequadas de oferta dessa etapa da educação básica em espaços comunitários da periferia da cidade, subjacente à insuficiência de vagas. O discurso dominante em 2009, que ainda permanece, é o da impossibilidade de os governos assumirem essa política pública. Esse quadro de carência e a premente necessidade de cuidado e educação das crianças induzem famílias de baixa renda, à aceitação de espaços, mesmo que inadequados, a seus filhos, e não estimula a comunidade a exigir melhor qualidade do poder público.

Outros destaques, apresentados por Susin (2009), referem-se ao processo de precarização dos salários dos profissionais, tanto pela des- 
valorização da remuneração dos professores, quanto pelo valor diferenciado pago aos trabalhadores numa mesma instituição. Ademais, percebe-se a fragilidade da gestão democrática nos espaços pesquisados, que apontam para a ausência de participação da comunidade, o que legitima o exercício autoritário da gestão. As decisões, desse modo, ficam centradas na direção da instituição e a participação da comunidade é restrita aos momentos festivos ou de reuniões, os pais tão somente a se comportar como espectadores, reforçando a autoridade do dirigente, cada vez mais autônomo a decidir sobre questões que deverão diretamente afetar a vida de dezenas de crianças e familiares. Todas essas práticas impactam o processo pedagógico e democrático, indispensáveis para se atingir uma educação de qualidade, ao mesmo tempo que têm implicações na democratização da educação.

\section{A Educação Infantil no Plano Nacional e no Plano Municipal de Educação}

O Plano Nacional de Educação (PNE), Lei Federal no 13.005, de 25 de junho de 2014 (Brasil, 2014a), estabelece, para todo o território nacional, as diretrizes e metas para a educação nos dez anos subsequentes, ou seja, até 2024, devendo os demais entes da federação elaborar seus próprios planos, em consonância com as suas determinações. Destaca-se que, na meta 1, o PNE define "Universalizar, até 2016, a educação infantil na pré-escola para as crianças de 4 (quatro) a 5 (cinco) anos de idade e ampliar a oferta de educação infantil em creches de forma a atender, no mínimo, 50\% (cinquenta por cento) das crianças de até 3 (três) anos até o final da vigência deste PNE” (PNE 2014-2024).

Com base no plano nacional, o município de Porto Alegre elaborou o Plano Municipal de Educação (PME), aprovado pela Lei no 11.858 , de 25 de junho de 2015. Nas metas e estratégias do PME, no que se refere à educação infantil, está consignado: Meta 1 - Atender a 100\% (cem por cento) de matrículas na pré-escola, até 2016, e ampliar, gradativamente, as matrículas na creche para atingir o percentual de $50 \%$ (cinquenta por cento) até 2024.

Algumas das estratégias definidas para o alcance dessas metas não se referem somente aos percentuais, mas às formas como esses percentuais serão alcançados. De acordo com a Estratégia 1.1, será necessário "definir ações para atender a $100 \%$ (cem por cento) das matrículas na faixa etária de 4 (quatro) a 6 (seis) anos", matrículas estas a serem "criadas e mantidas preferencialmente pela rede municipal e conveniada, em tempo integral e numa concepção de educação integral conforme a legislação vigente [...]". A estratégia 1.3 estabelece: “[...] ampliar a rede pública estatal, priorizando a educação infantil dentro de sua estrutura física e de pessoal e, quando necessária, a adequação desta estrutura”. A estratégia 1.7 propõe que a expansão da pré-escola não perca de vista a qualidade no atendimento "[...] e as especificidades da escola de qualidade para as infâncias, ampliando a rede pública estatal [...]”, bem como na estratégia 1.10 “[...] garantir o acesso e a permanência na 
A Relação Público-Privada na Oferta da Educação Infantil em Porto Alegre

educação infantil na rede municipal, em tempo integral e numa concepção integral de educação, para todas as crianças de 0 (zero) a 6 (seis) anos, considerando a data de corte, conforme estabelecido nas Diretrizes Curriculares Nacionais para a Educação Infantil [...]" (Porto Alegre, 2015, n.p.).

Se considerarmos os números informados na Portaria Interministerial no 10, de 28 de dezembro de 2017 (Brasil, 2017), quanto às matrículas da educação infantil em Porto Alegre, para fins de Fundo de Manutenção e Desenvolvimento da Educação Básica e de Valorização dos Profissionais da Educação (Fundeb), o município não cumpriu a meta 1 e as estratégias dessa meta, constantes do PME/2015, pois podemos observar que, conforme o estudo de Susin (2009) citado anteriormente, o processo de parceria apresenta problemas no que se refere à qualidade. Ademais, o crescimento das matrículas da educação infantil parceira, segundo o Quadro 3, é, numericamente, muito superior às matrículas públicas, em 2018.

Quadro 3 - Matrículas Educação Infantil-FUNDEB/2018

\begin{tabular}{|c|c|c|c|c|c|c|c|}
\hline \multicolumn{4}{|c|}{ Instituições públicas } & \multicolumn{3}{c|}{ Instituições Sociedade Civil } \\
\hline $\begin{array}{c}\text { Creche } \\
\text { integral }\end{array}$ & $\begin{array}{c}\text { Creche } \\
\text { parcial }\end{array}$ & $\begin{array}{c}\text { Pré-escola } \\
\text { Integral }\end{array}$ & $\begin{array}{c}\text { Pré-escola } \\
\text { parcial }\end{array}$ & $\begin{array}{c}\text { Creche } \\
\text { integral }\end{array}$ & $\begin{array}{c}\text { Creche } \\
\text { parcial }\end{array}$ & $\begin{array}{c}\text { Pré-escola } \\
\text { Integral }\end{array}$ & $\begin{array}{c}\text { Pré-escola } \\
\text { parcial }\end{array}$ \\
\hline 2.187 & 36 & 3.096 & 2.682 & 7.721 & 52 & 6.613 & 288 \\
\hline \multicolumn{2}{|c|}{ Total } & \multicolumn{2}{c|}{ Total } & Total \\
\hline \multicolumn{2}{|c|}{5.578} & \multicolumn{3}{c|}{7.773} & \multicolumn{3}{c|}{ Total oferta sociedade civil } \\
\hline \multicolumn{3}{|c|}{2.223} & \multicolumn{3}{c|}{14.674} \\
\hline
\end{tabular}

Fonte: Elaboração dos autores com base nos dados do Relatório Anual de Monitoramento do Plano Municipal de Educação (2018).

De acordo com o Relatório Anual de Monitoramento do Plano Municipal de Educação/2018, referente ao ano de 2017, a tabela que apresenta o percentual da população de 4 a 5 anos que frequenta a escola/ creche informa o percentual de $73,24 \%$, enquanto o percentual da população de 0 a 3 anos frequentando a escola/creche é de $31,40 \%$ (Porto Alegre, 2018, p. 8). Percentuais que nos permitem inferir o descumprimento da meta 1 dos Planos Estadual e Municipal de Educação.

Faz-se necessário considerar que estudos feitos pela Campanha Nacional pelo Direito à Educação já definiram o Custo Aluno Qualidade inicial (CAQi), como referência, prevendo avanço para um patamar superior, o Custo Aluno Qualidade (CAQ), que, em termos de valores anuais, está bem acima do proposto pelo Fundeb. Esses referenciais propostos pela Campanha estão consubstanciados na Meta 20 e estratégias 20.6 e 20.8 do Plano Nacional de Educação 2014/2024.

20.6) no prazo de 2 (dois) anos da vigência deste PNE, será implantado o Custo Aluno-Qualidade inicial - CAQi, referenciado no conjunto de padrões mínimos estabelecidos na legislação educacional e cujo financiamento será cal- 
culado com base nos respectivos insumos indispensáveis ao processo de ensino-aprendizagem e será progressivamente reajustado até a implementação plena do Custo Aluno Qualidade - CAQ;

[...]

20.8) o CAQ será definido no prazo de 3 (três) anos e será continuamente ajustado, com base em metodologia formulada pelo Ministério da Educação - MEC, e acompanhado pelo Fórum Nacional de Educação - FNE, pelo Conselho Nacional de Educação - CNE e pelas Comissões de Educação da Câmara dos Deputados e de Educação, Cultura e Esportes do Senado Federal (PNE 2014-2014).

Destaca-se ainda que esses mesmos referenciais estavam presentes em documento do Conselho Nacional de Educacão, Parecer CNE/ CEB no 8, de 05 de maio de 2010 (Brasil, 2010), que "Estabelece normas para aplicação do inciso IX do artigo $4^{\circ}$ da Lei no 9.394 , de 20 de dezembro de 96, Lei de Diretrizes e Bases da Educação (LDB), que trata dos padrões mínimos de qualidade de ensino para a Educação Básica pública" (Brasil, 2010). O referido parecer não foi homologado e, no ano de 2019, a Câmara de Educação Básica reexaminou a matéria posicionando-se contrariamente à definição do valor financeiro e à precificação do Custo Aluno Qualidade inicial (CAQi) definida no referido Parecer. Essa decisão, somada ao conteúdo da Emenda Constitucional (EC) n ${ }^{\circ}$ 95, de 15 de dezembro de 2016 (Brasil, 2016), que cria um teto para os gastos públicos, como educação, saúde e assistência social, por 20 anos, é preocupante, pois posterga para muito distante o horizonte que se vislumbrava para a qualificação da educação no Brasil.

Salientamos que o Fundeb, política de financiamento da educação básica, com prazo determinado de vigência até 2020 exige nova regulamentação para o financiamento da educação, o que ocorreu com a Lei no 14.113, de 25 de dezembro de 2020.

A especificidade da educação infantil, tanto no que se refere à reduzida proporção professor/aluno, bem como ao espaço físico, que ao mesmo tempo precisa ser desafiador, acolhedor, estimulador e seguro, e o material pedagógico variado, adequado e em número suficiente, dentre outros, exige um custo/aluno/ano muito mais elevado do que aquele definido pelo Fundeb. Conforme Evaldo Vieira (2004, p. 19) “[...] é imprescindível fundamentar, proclamar e proteger os direitos sociais". A questão que se coloca é: repassar a gestão da educação infantil para a sociedade civil significa assegurar direitos?

De acordo com os dados do Tribunal de Contas do Estado do Rio Grande do Sul, divulgados em 2018, no documento intitulado Radiografia da Educação Infantil (Quadro 4), que tem como base o censo educacional de 2010, o déficit das matrículas para a educação infantil em Porto Alegre, para o atendimento da Meta 1 do PNE 2014/2024, exige a necessidade da criação de 13.221 vagas na educação infantil, sendo 6.757 matrículas para crianças de 0 a 3 anos e 6.464 matrículas para crianças de 4 a 5 anos. 
A Relação Público-Privada na Oferta da Educação Infantil em Porto Alegre

Quadro 4 - Educação Infantil no RS/Município de Porto Alegre/2018

\begin{tabular}{|c|c|c|c|c|c|c|c|c|}
\hline \multicolumn{2}{|c|}{ Idade das crianças } & \multicolumn{4}{c|}{ Taxa de Atendimento } & \multicolumn{3}{c|}{ Necessidade novas vagas } \\
PNE
\end{tabular}

Fonte: Elaborado pelas autoras com base nos dados do Relatório Tribunal de Contas do RS, 2018 (utiliza dados do Censo Demográfico IBGE 2010 e do Censo Escolar INEP 2017).

A necessidade de superar esse limite, representado pelo acesso restrito das crianças à educação infantil, em Porto Alegre, sinaliza para a busca de alternativas de modo a garantir os direitos da criança e das famílias em espaços públicos de qualidade, que dificilmente serão desencadeadas pelas associações de moradores, considerando a posição dos dirigentes e das entidades representativas das creches comunitárias. A naturalização do envolvimento da sociedade civil na oferta de políticas públicas despolitiza os conflitos sociais, bem como neutraliza as contradições que permitem avançar na luta pelo papel do Estado no direito à educação.

\section{As Parcerias como Materialização das Redefinições no Papel do Estado}

No município de Porto Alegre, as instituições comunitárias, bem como as privadas, têm uma relação de parceria com o poder público e conforme números já apresentados no quadro 2 acima, isso se caracteriza como a política preferencial do município na oferta de educação infantil que, ainda assim, não consegue alcançar as metas previstas no PME 2015/2024.

De acordo com texto do Secretário Municipal de Educação de Porto Alegre, Adriano Naves de Brito (2018) "Gestão Pública do ecossistema municipal de Educação: o caso de Porto Alegre", a educação como direito tem duplo sentido, "o passivo", direito daquele que deve recebê-lo e "o ativo" daqueles que devem ofertá-lo, e "Não importa a natureza institucional da escola, se pública estatal, pública não estatal ou privada" (Brito, 2018, p. 113).

Ao afirmar a obrigatoriedade da oferta de educação pelo Estado, o Secretário destaca que "respeitados os marcos legais" todos têm direito a essa oferta. Além disso, o Secretário define o Sistema Educacional como "um ecossistema educacional diversificado e rico [...]" no qual:

Há instituições públicas, mas não estatais, em móveis públicos e com gestão comunitária; instituições comunitárias financiadas exclusivamente com recursos públicos; instituições filantrópicas que recebem benefícios públicos para oferta pública e privada de educação; instituições público-estatais com acesso a recursos privados para a sua gestão; instituições cujos alunos contam para o 
ente público para fins de financiamento, mas cuja gestão é da sociedade civil e assim por diante, numa mestiçagem que é virtuosa desde que as atividades da população de qualquer desses ecossistemas seja coordenada sob a perspectiva do interesse público e, portanto, pelo Estado que o representa (Brito, 2018, p. 114).

Ainda segundo o Secretário Municipal de Educação, em artigo publicado no Jornal Folha de São Paulo, de 13 de julho de 2020, "Para um novo Fundeb, o tempo não é agora", a proposta de um novo fundo para a educação básica "não devia ser votada neste ano". E elenca razões para fundamentar sua afirmação. "A primeira, e mais óbvia, é a pandemia" e o cenário confuso dela decorrente, no qual seria votada a lei de regulação do fundo (Brito, 2020, n. p). A segunda, a necessária reforma tributária e administrativa e os impactos imprevisíveis nos recursos humanos e tributários, pós-pandemia e a terceira, "de cunho mais conceitual" é quanto a pertinência da constitucionalização da redistribuição de recursos "para entes públicos estatais que são parte de um sistema muito mais plural de oferta de educação" (Brito, 2020, n. p).

Para o Secretário, "[...] o vício de origem da proposta em discussão é que a atual lei veda o uso de recursos do fundo para alunos regulares do ensino fundamental e médio que não sejam de escolas públicas estatais". E, por estas razões, propõe a prorrogação da atual lei "por mais quatro anos, [...] sem as limitações do uso de seus recursos para custear os alunos da educação básica pública não estatal" (Brito, 2020, n. p).

$\mathrm{O}$ debate acerca da responsabilidade em atender o direito à educação, diluída entre o público estatal e o público não estatal, ou seja, entre o Estado e a sociedade civil, pode ser analisado como parte das reformas de segunda geração do neoliberalismo proposta pelo Consenso de Washington, que tem como foco a reforma estatal e suas implicações, com destaque para o protagonismo das Organizações Não Governamentais (ONG) e o papel do empreendimento. "Las denominadas reformas de Segunda Generación, las cuales dirigen su interés en torno a las reformas políticas e institucionales han estado dominadas por el tema de la reforma estatal y sus implicaciones" (Puello- Socarrás, 2008, p. 103).

Para o autor, o neoliberalismo se fortaleceu com a crise de 2008: "El neoliberalismo hoy por hoy lejos de agotarse se reedita". Esta reestruturação tem como base o estado empresarial: "El gobierno empresarial limitaría su rol a la regulación pública, evitando la prestación directa de los servicios sociales, manteniendo niveles óptimos de competencia e impidiendo al máximo las situaciones monopólicas y las interferencias en el mercado" (Puello-Socarrás, 2008, p. 113).

Puello-Socarrás (2008, p.108) apresenta o público não estatal como a tendência das reformas de segunda geração:

Así se promociona un dominio que desvincula 'lo público' de 'lo estatal' en una especie de 'espacio público-privado', o como se lo ha denominado un 'espacio público no-es- 
A Relação Público-Privada na Oferta da Educação Infantil em Porto Alegre

tatal' que resulta abierta y fundamentalmente mercantil (como el mismo status ontológico del Mercado: un dominio que no es exclusivamente privado sino estrictamente público-privado, es decir, un locus público donde las mercancías tienen la posibilidad de intercambiarse entre ellas para posteriormente privatizarse).

O autor adverte para as consequências das mudanças:

Esta forma pública no-estatal de intervención institucional, por supuesto, tiene grandes implicaciones. Pero, seguramente la más arquitectónica es su pretensión de profundizar la univocidad de la lógica mercantil en el terreno del aparato estatal y en las relaciones políticas que estructuran la totalidad de 'lo social' actualmente (Puello-Socarrás, 2008, p. 108).

Neste processo, o autor aponta algumas consequências sociais como o foco no individualismo, já que o empreendedor é sempre o indivíduo, o esfumaçamento das relações capital trabalho, a flexibilização laboral, inclusive as que acontecem via economia solidária e cooperativas de trabalho.

llaman la atención la sospechosa 're-invocación' y el protagonismo público que han ganado distintas formas de Voluntariado y actividades de ONG's y de la Economía Solidaria, el conocido 'tercer sector' en el cual se han recodificado distintas acciones socio-económicas pero que se han dirigido a desestructurar el campo estatal y todo lo que ello significa, sobre todo, en materia de derechos constitucionales y la seguridad social, específicamente, frente a las regulaciones laborales prevalecientes que suponen obstáculos y 'cargas' para la actual acumulación capitalista del neo-liberalismo, favoreciendo al Capital (Puello-Socarrás, 2008, p. 97).

A política de parceria materializa esta proposta e vem adquirindo expressão na sociedade, alterando o padrão de intervenção estatal na oferta de educação infantil, cujas discussões passam a legitimar o afastamento do Estado dessa política, com justificativas que se pautam nas dificuldades econômicas.

Observa-se também que a política impressa para o conveniamento/parceria atende ao disposto por organizações multilaterais, em suas diretrizes políticas para a educação, alinhadas ao corolário da Conferência Internacional de Educação para Todos, realizada em 1990. Essas orientações, que perduram até o momento atual, vêm acompanhadas de inovações drásticas para a educação pública, como pode se verificar no Relatório do Banco Mundial (2011), Educação Infantil: programas para a geração mais importante do Brasil, que realiza estudo sobre a qualidade da Educação no Brasil e apresenta ações para que o País cumpra a universalização da pré-escola. Esse relatório traz uma análise da oferta da educação infantil, não a partir do direito à educação, conforme consagrado na Constituição Federal de 05 de outubro de 1988 
(Brasil, 1988), mas como resolução de problemas sociais, e tem como parâmetro o crescimento econômico, considerando essa oferta como investimento. O documento estimula a parceria público-privada como forma eficaz para a prestação do serviço, exemplificando de forma positiva a contratação de educação infantil por meio da parceria, conforme apontado no "Capítulo 1: Educação Infantil: Prioridade para os próximos anos [...]" nos "[...] passos para o Desenvolvimento na Primeira Infância para o Brasil”:

Muitos outros países conseguiram incorporar o apoio do setor privado de forma eficaz para prestar serviços para o Desenvolvimento na Primeira Infância em larga escala. Isso pode incluir o fornecimento direto, como o Brasil faz por meio de creches e pré-escolas contratadas (conveniadas) pelo governo. Também pode incluir parcerias para aumentar o financiamento público - provavelmente essencial em face da expansão massiva necessária no Brasil (Banco Mundial, 2011, p. 14).

É preciso enfatizar que o poder público lançou mão dos convênios para a educação infantil, em uma conjuntura de passagem das creches, da assistência social, para a educação, da inexistência de um fundo específico para a educação infantil, o que incentivou as parcerias entre o público e o privado para oferta, com a naturalização do possível (Peroni, 2013a). Passadas duas décadas, a situação de excepcionalidade já não persiste e o que se coloca no momento é a necessidade da oferta de educação pública, gratuita, laica e de qualidade para todas as crianças de zero a seis anos de idade - oferta que deve ocorrer dentro de parâmetros de qualidade que respeitem a criança e os seus direitos.

Entendemos que os problemas enfrentados pela política de conveniamento, que hoje dá lugar à parceria da educação infantil, são consequências do pressuposto de que o Estado não deve ser mais o executor direto das políticas sociais, repassando assim, para a sociedade civil, as suas responsabilidades. Conforme mencionamos no início do artigo, tal concepção tem por base o diagnóstico de que o Estado é o culpado pela atual crise, de diminuição da taxa de lucros por parte do capital, pois provoca a crise fiscal ao atender as demandas sociais. Para as políticas sociais, a estratégia é a parceria público-privada, tanto para racionalizar recursos, quanto porque defende que assim promoverá a democratização do espaço público, através do fortalecimento do público não estatal, de propriedade privada, como é o caso das creches comunitárias.

Com essa concepção de democracia, a sociedade é chamada a executar tarefas, até então de incumbência estatal, em nome de sentimentos como filantropia ou ajuda mútua. Entendemos que, perante esse cenário ocorre o esvaziamento do conteúdo da democracia, pois há a separação entre o econômico e o político, além da perda da ideia de direitos sociais materializados em políticas públicas. O esvaziamento do conteúdo da democracia e a separação entre o econômico e o político são evidentes. Perdeu-se a discussão das políticas sociais como a materialização de direitos sociais (Peroni, 2013c). 
A Relação Público-Privada na Oferta da Educação Infantil em Porto Alegre

Uma das grandes lutas do período de democratização da sociedade brasileira foi a ampliação do direito à educação, mas, assim como as outras políticas sociais, a efetivação do direito, ao se materializar em políticas, foi amplamente modificada com as redefinições do papel do Estado. Ellen Wood (2003, p. 193) destaca que o conceito de democracia em uma sociedade sob a hegemonia do capitalismo não pode ser visto em abstrato, pois, afinal: "É o capitalismo que torna possível uma forma de democracia em que a igualdade formal de direitos políticos tem efeito mínimo sobre as desigualdades ou sobre as relações de dominação e de exploração em outras esferas".

Entendemos que o processo democrático se dá como parte da correlação de forças políticas. Os interesses de classe perpassam a sociedade civil e o Estado, portanto, urge localizar o debate em um contexto próprio, no qual o Estado se retira das políticas sociais e as repassa para a sociedade, o que culmina em perdas de direitos. A política de conveniamento materializa essa proposta, retira do poder público o dever da oferta pública às crianças pequenas, delegando à sociedade o atendimento das suas necessidades. A reconfiguração do Estado, cada vez mais enxuto para os investimentos sociais e generoso para com o capital, retrata a sua submissão ao jogo econômico, que justifica e direciona as decisões políticas para investimentos mais rentáveis, com o Estado assumindo a defesa dos interesses do capital.

O capital cada vez mais recorre ao Estado para que este exerça as funções de controle necessárias à garantia da expansão e da acumulação, molas propulsoras da economia capitalista, a contradizer a teoria neoliberal de Estado mínimo. O que presenciamos é um Estado máximo para o capital e mínimo para as políticas sociais (Peroni, 2003). Exercendo as exigências sobre ele depositadas, e para não onerar o capital além do limite permitido, o Estado atende às demandas sociais com políticas focalizadas e de baixo custo. É a partir dessa realidade que se questiona a minimização do Estado para com as políticas sociais.

As garantias do Estado para a expansão do capital, em detrimento do direito ao trabalho e de direitos sociais, aumentam a dificuldade na conquista de novos direitos, bem como na qualificação daqueles já alcançados. Esse cenário está presente nas sociedades capitalistas e se aprofunda nos períodos de crise, haja vista a crise iniciada em setembro de 2008. Com o político isolado da sua base material, os recursos destinados ao capital financeiro em detrimento das políticas sociais assumem caráter inexorável e reforçam a cultura do direito possível e da qualidade possível, no caso das políticas sociais (Peroni, 2016; Ribeiro, 2002).

De acordo com Susin (2005) a educação infantil pública, no Brasil, ao longo da sua história, pauta-se por uma política pontual voltada para as famílias de baixa renda, cuja qualidade inicialmente (anos 1970) é ditada pelos organismos internacionais e assumida pelo Estado brasileiro, por meio de ações não formais e de baixo custo. Isso fez com que a educação infantil tivesse, desde o seu nascedouro, um histórico de ausência de investimentos, espaços improvisados e inadequados. No- 
tamos, desse modo, a prática de ações assistenciais que não asseguram qualquer direito às crianças pequenas, sem conteúdo educativo institucional e a cargo de cidadãos de boa vontade, que assumiam o cuidado dessas crianças, na pessoa de educadores voluntários ou de educadores mal remunerados, realidade ainda hoje presente nesse meio.

No período pós-ditadura, entre as grandes lutas de democratização da sociedade ${ }^{4}$, esteve a ampliação do direito à educação e o dever do Estado em executá-lo. No caso da educação infantil, passá-la da assistência para a educação foi um grande avanço, resultado de lutas sociais, assim como a sua incorporação na Educação Básica, juntamente com o ensino fundamental e o ensino médio. A luta pela democracia esteve invariavelmente conjugada à luta por direitos sociais materializados em políticas públicas. Hoje, o Estado opta pela parceria para o atendimento das políticas públicas, estratégia que não assegura direitos e fragiliza as demandas da população nas pontas mais frágeis: crianças pequenas, idosos e deficientes.

Se, por um lado, após muitas lutas, garantimos o direito à educação como parte dos direitos sociais, pela democratização da sociedade e a gestão democrática da educação, por outro, o mundo já vivia uma crise do capitalismo ${ }^{5}$ e suas estratégias de superação - neoliberalismo, globalização, reestruturação produtiva e Terceira Via -, que redefinem o papel do Estado e diminuem a sua atuação como executor das políticas sociais. Vivemos, portanto, a tensão entre ter conquistado direitos, inclusive na legislação, e a dificuldade para sua implementação.

Evaldo Vieira (2004) faz essa discussão quando analisa que, em nosso país, as políticas sociais percorreram três momentos políticos no último século: “[...] o primeiro período de controle da política (que corresponde à ditadura de Getúlio Vargas e ao populismo nacionalista); o segundo período de política do controle (da ditadura militar em 1964 até o final do período constituinte em 1988)" e o terceiro período, denominado pelo autor de "política social sem direitos sociais", iniciou-se em 1988 e está em plena vigência. A política social que, por um lado, nunca havia recebido tanto acolhimento por parte de uma constituição no Brasil, como ocorreu na Carta de 1988, por outro, viu esses direitos praticados de forma precarizada e nem sempre regulamentados (quando exigiam regulamentação). A conjuntura atual, no entanto, revela que os poucos direitos, garantidos na Carta de 1988, estão sendo eliminados ou metamorfoseados no intuito de garantir a supressão das responsabilidades do Estado. Concordamos com Vieira de que, neste momento "[...] tidas como naturais e independentes, as leis da economia lamentavelmente transmitem a impressão de que se extinguem as sociedades, sobrevivendo apenas os mercados e os grupos unidos a ele [...]" (Vieira, 1998, p. 68).

\section{Considerações Finais}

Conforme já afirmado neste artigo, em uma sociedade de classes, a concentração de riqueza corrobora no acirramento das desigualda- 
A Relação Público-Privada na Oferta da Educação Infantil em Porto Alegre

des, não existindo condições objetivas de promoção de direitos iguais, nem mesmo igualdade de condições de acesso aos bens produzidos pelo trabalho. A qualidade das políticas públicas também é marcada por essa realidade, e condições econômicas mais favoráveis dimensionam a qualidade dos serviços ofertados, o que não é diferente na educação infantil aqui analisada.

Nesse contexto social se insere a educação infantil no Brasil, que desde o seu início convive com um histórico de ausência de investimentos, espaços inapropriados e prática de ações assistenciais que não asseguram direito às crianças pequenas.

A oferta de educação infantil, com a qualidade assegurada como direito de toda a criança pequena, dar-se-á por meio de uma educação pública e gratuita, caso contrário, terá acesso a esse direito, como já acontece, somente quem pode arcar com seus custos, transformando a educação em mercadoria.

Os movimentos sociais, em âmbito nacional, quando da Constituinte, lutavam pela educação infantil como direito a partir de zero até os seis anos de idade, o que foi materializado no Art. 208, inciso IV, da Constituição Federal de 1988 (Brasil, 1988). Com o cômputo das matrículas das creches comunitárias no Fundeb (2007), naturalizou-se novamente a ideia de filantropia na oferta da educação infantil, principalmente da creche. Em Porto Alegre, a educação infantil comunitária foi a alternativa de que lançou mão o poder público municipal, em 1993, quando o movimento social local reivindicava educação para as crianças pequenas. A resposta a essas reivindicações, que deveria ser transitória, tornou-se a política de educação infantil no município, conforme evidenciam os dados de matrícula. Em 2019, temos uma rede comunitária com 15.564 matrículas, e uma rede pública infinitamente menor, com 7.975 matrículas.

O direito à educação, constitucionalmente previsto, está associado a um padrão de qualidade para todos, por conseguinte, o direito ao acesso e à qualidade não pode ser lido isoladamente. A necessidade de superar os limites representados pelo acesso restrito das crianças à educação infantil na escola pública, em Porto Alegre, sinaliza para a busca de alternativas à garantia dos direitos da criança e das famílias a políticas sociais de qualidade.

O nebuloso entendimento sobre o que é público ou privado, a partir da concepção de público estatal e público não estatal e, que nos anos de 1990 norteou, e continua justificando o afastamento do Estado na garantia dos direitos sociais, não pode servir como pretexto para a permanência e ampliação da política de parceria. Todos os limites evidenciados no avanço da oferta de educação infantil pública fazem parte de uma realidade de diminuição do papel do Estado como garantidor de uma educação de qualidade. Trata-se de um debate urgente, que deve se dar no contexto de um Estado que repassa parte das políticas sociais para a sociedade civil. Enfatizamos que a política educacional é parte constitutiva das redefinições do papel do Estado, e materializa a correlação de forças que ocorre na sociedade. 
É nesse contexto de definição da política educacional que se coloca a importância da qualidade da educação, a começar pela educação infantil, e se chama a atenção para o fortalecimento de todos os espaços de participação na busca da superação das relações excludentes desta sociedade de classe.

Embora Porto Alegre tenha ampliado as vagas, na oferta da educação infantil, essa ocorreu, conforme demonstramos nesse texto, via parceria entre o público e o privado, com a responsabilização da sociedade civil, que o faz do jeito que é possível, com largas distinções, no atendimento conforme a situação social de cada comunidade. Assim temos, conforme Susin (2009), diferentes qualidades na oferta de acordo com a situação social de cada comunidade. Desta forma, ocorre o que chamamos de naturalização do possível, com a minimização de direitos e forte implicações para a democratização da educação.

Recebido em 25 de julho de 2020 Aprovado em 10 de maio de 2021

\section{Notas}

1 Implicações da relação público-privado para a democratização da educação na América Latina: Uruguai, Argentina, Venezuela, Chile, Bolívia e Brasil. Disponível em: <https://www.ufrgs.br/gprppe/?page_id=77>. Acesso em: 22 abr. 2021.

2 Programa Dinheiro Direto na Escola: uma proposta de redefinição do papel do Estado na educação? (2005); Novos contornos da parceria público/privada na Gestão da Escola Pública (2011); Análise das consequências de parcerias firmadas entre municípios brasileiros e a fundação Ayrton Senna para a oferta educacional (2011); Parcerias entre sistemas públicos e instituições do terceiro setor: Brasil, Argentina, Portugal e Inglaterra: implicações para a democratização da educação (2013); Implicações da relação público- privada para a democratização da educação: Brasil, Portugal e Inglaterra (2015). Disponível em: <https://www.ufrgs.br/gprppe/?page_id=77>. Acesso em: 22 abr. 2021.

3 O período analisado teve como base a lei no 11.494, de 20 de junho de 2007, revogada pela Lei $n^{\circ} 14.113$, de 25 de dezembro de 2021.

4 Movimentos da sociedade civil em prol de direitos políticos e sociais voltados para a educação na infância na década de 1980, tais como: Movimento pela Constituinte, Movimento das Mulheres, Fórum Nacional em Defesa da Educação Pública; Fórum em defesa da Criança e do Adolescente pelo Grupo Ação Vida e pelo Conselho das Mulheres; Movimento de Luta por Creches (1979), de São Paulo e o segundo Congresso da Mulher Paulista, na década de 1980, dentre outros.

5 Crise do capitalismo, aqui entendida como diminuição da taxa de lucro.

\section{Referências}

ABDALA, Paulo Ricardo Zilio; PUELLO-SOCARRÁS, José Francisco. Reflexiones sobre la administración pública y el neoliberalismo en nuestramérica, siglo XXI. Revista Eletrônica de Administração, Porto Alegre, v. 25, n. 2, p. 22-39, maio 2019.

Educação \& Realidade, Porto Alegre, v. 46, n. 3, e105676, 2021. 
A Relação Público-Privada na Oferta da Educação Infantil em Porto Alegre

ADRIÃO, Theresa Maria de Freitas; PERONI, Vera Maria Vidal. Consequências da atuação do Instituto Ayrton Senna para a gestão da educação pública: observações sobre dez casos em estudo. Revista Práxis Educativa, Ponta Grossa, v. 6, n. 1, jan./jul. 2011.

BANCO MUNDIAL. Educação Infantil: Programa para a Geração Mais Importante do Brasil. Relatores: David K. Evans e Katrina Kosec. Tradução: Fundação Maria Cecília Souto Vidigal. São Paulo: Banco Mundial, 2011.

BRASIL. Constituição da República Federativa do Brasil de 1988. Diário Oficial da União, Brasília, 05 out. 1988. P. 1. Disponível em: <http://www. planalto.gov.br/ccivil_03/constituicao/constituicao.htm>. Acesso em: 20 jan. 2019.

BRASIL. Lei Federal no 11.494, de 20 de junho de 2007. Fundo de Manutenção e Desenvolvimento da Educação Básica e de Valorização dos Profissionais da Educação - FUNDEB. Diário Oficial da União, Brasília, 2007. Disponível em: <http://www.planalto.gov.br/ccivil_03/_ato2007-2010/2007/lei/111494. htm>. Acesso em: 01 jul. 2019.

BRASIL. Ministério da Educação, Conselho Nacional de Educação. Câmara de Educação Básica. Parecer CNE/CEB no 20, de 12 de dezembro de 2009. Revisão das Diretrizes Curriculares Nacionais para a Educação Infantil. Brasília, 2009. Disponível em <http://portal.mec.gov.br/conselho-nacional-de-educacao/apresentacao >. Acesso em: 03 jul. 2019.

BRASIL. Ministério da Educação. Conselho Nacional de Educação. Parecer CNE/CEB no 8/2010, de 05 de maio de 2010. Estabelece normas para aplicação do inciso IX do artigo $4^{\circ}$ da Lei no 9.394/96 (LDB), que trata dos padrões mínimos de qualidade de ensino para a Educação Básica pública. Brasília, 2010. Disponível em: <http://portal.mec.gov.br/index.php?option=com docman\&view=download\&alias=5368-pceb008-10\&category_slug=maio2010-pdf\&Itemid=30192>. Acesso em: 03 jul. 2019.

BRASIL. Lei no 13.005, de 25 de junho de 2014. Aprova o Plano Nacional de Educação - PNE e dá outras providências. Diário Oficial da União, Brasília, 2014a. Disponível em: <http://www.planalto.gov.br/ccivil_03/_ato20112014/2014/lei/l13005.htm>. Acesso em: 01 jul. 2019.

BRASIL. Lei no 13.019, de 31 de julho de 2014. Estabelece o regime jurídico das parcerias entre a administração pública e as organizações da sociedade civil, em regime de mútua cooperação, para a consecução de finalidades de interesse público e recíproco. Diário Oficial da União, Brasília, 01 ago. 2014b. P. 1. Disponível em: <http://www.planalto.gov.br/ccivil_03/_ato20112014/2014/lei/l13019.htm>. Acesso em: 01 jul. 2019.

BRASIL. Emenda Constitucional no 95 de 2016. Altera o Ato das Disposições Constitucionais Transitórias, para instituir o Novo Regime Fiscal, e dá outras providências. Diário Oficial da União, Brasília, 16 dez. 2016. P. 2. Disponível em: <https://legis.senado.leg.br/norma/540698>. Acesso em: 05 ago. 2019.

BRASIL. Portaria interministerial no 10, de 28 de dezembro de 2017. Diário Oficial da União, Brasília, 28 dez. 2017. P. 14. Disponível em: <https://www. in.gov.br/web/guest/materia/-/asset_publisher/Kujrw0TZC2Mb/content/ $\mathrm{id} / 1498280 /$ do1-2017-12-29-portaria-interministerial-n-10-de-28-de-dezembro-de-2017-1498276>. Acesso em: 05 dez. 2019.

BRITO, Adriano Naves de. Gestão Pública do ecossistema municipal de Educação: o caso de Porto Alegre. In: OGIBA, Sonia Maria M. (Org.). Garan- 
tia do Direito à Educação: monitorando o PNE - Lei no $13.005 / 2014$. Porto Alegre: Editora da UFRGS, 2018. P. 113-119.

BRITO, Adriano Naves de. Para um novo Fundeb, o tempo não é agora. Folha de São Paulo, São Paulo, 12 de julho de 2020. Disponível em: <https:// wwwl.folha.uol.com.br/opiniao/2020/07/para-um-novo-fundeb-o-temponao-e-agora.shtml>. Acesso em: 13 jul. 2020.

MONTAÑO, Carlos. Terceiro Setor e a Questão Social: crítica ao padrão emergente de intervenção social. São Paulo: Cortez, 2002.

MONTANO, Monique Robain. A parceria entre a administração pública e as entidades privadas sem fins lucrativos a partir do marco regulatório das organizações da sociedade civil (MROSC) na oferta da educação infantil em Porto Alegre. 2018. 215 f. Dissertação (Mestrado em Educação) - Programa de Pós-Graduação em Educação, Faculdade de Educação, Universidade Federal do Rio Grande do Sul, Porto Alegre, 2018.

PERONI, Vera Maria Vidal. Política educacional e papel do Estado: No Brasil dos Anos 1990. São Paulo: Xamã Editora, 2003.

PERONI, Vera Maria Vidal. As Relações entre o Público e o Privado nas Políticas Educacionais no Contexto da Terceira Via. Currículo sem Fronteiras, v. 13, n. 2, maio/ago. 2013a.

PERONI, Vera Maria Vidal (Org.). Redefinições das fronteiras entre o público e o privado: implicações para a democratização da educação. Brasília: Liber Livro, 2013b.

PERONI, Vera Maria Vidal. Redefinições no papel do Estado: parcerias público-privadas e a democratização da educação. Archivos Analíticos de Políticas Educativas, Tempe, v. 21, p. 1-20, 2013c.

PERONI, Vera Maria Vidal. Implicações da Relação Público-privada para a Democratização da Educação. 2016. Tese (Promoção à professora titular) Universidade Federal do Rio Grande do Sul, Porto Alegre, 2016.

PERONI, Vera Maria Vidal. Múltiplas formas de materialização do privado na educação básica pública no Brasil: sujeitos e conteúdo da proposta. Currículo sem Fronteiras, v. 18, p. 1-27, 2018.

PERONI, Vera Maria Vidal; ADRIÃO, Theresa Maria de Freitas. Programa Dinheiro Direto na Escola: uma proposta de redefinição do papel do Estado na educação? Brasília: INEP, 2007.

PERONI, Vera Maria Vidal; LIMA, Paula Valim de; KADER, Carolina Rosa (Org.). Redefinições das fronteiras entre o público e o privado: implicações para a democratização da educação. São Leopoldo: Oikos, 2015.

PORTO ALEGRE. Boletim SMED, 2011. Matrícula Inicial na Rede Municipal de Ensino de Porto Alegre. Dados estimados para 2010, publicado em 2011. Porto Alegre, 2011.

PORTO ALEGRE. Lei Municipal no 11.858, de 25 de junho de 2015. Institui o Plano Municipal de Educação (PME). Diário Oficial do Município de Porto Alegre, Porto Alegre, 2015. Disponível em: <http://lproweb.procempa.com.

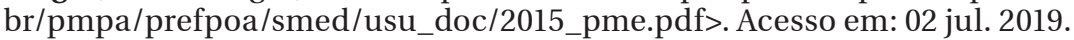

PORTO ALEGRE. Decreto no 19.775, de 27 de junho de 2017. Regulamenta a aplicação da Lei Federal n. 13.019, de 31 de julho de 2014 - que estabelece o regime jurídico das parcerias entre a administração pública e as organizações da sociedade civil, em regime de mútua cooperação. Diário Oficial do Município de Porto Alegre, Porto Alegre, 27 jun. 2017. Disponível em: 
A Relação Público-Privada na Oferta da Educação Infantil em Porto Alegre

<http://lproweb.procempa.com.br/pmpa/prefpoa/ppp/usu_doc/decreto_19775.pdf >. Acesso em: 01 jul. 2019.

PORTO ALEGRE. Relatório Anual de Monitoramento do Plano Municipal de Educação - PME. Período 2017. Porto Alegre, 2018. Disponível em: <https://websmed.portoalegre.rs.gov.br/escolas/fmepoa/index.htm>. Acessado em: 20 jan. 2019.

PUELLO-SOCARRÁS, José Francisco. Nueva gramática del neo-liberalismo: itinerarios teóricos, trayectorias intelectuales, claves ideológicas. Bogotá: Universidad Nacional de Colombia. Facultad de Derecho, 2008.

RIBEIRO, Marlene. Educação para a cidadania. Educação e Pesquisa, São Paulo, v. 28, n. 2, p. 113-128, jul./dez. 2002.

RIKOWSKI, Glenn. Privatização em educação e formas de mercadoria. Revista Retratos da Escola, Brasília, v. 11, n. 21, p. 393-413, jul./dez. 2017.

RIO GRANDE DO SUL. Tribunal de Contas do Estado. Educação Infantil: A primeira infância relegada à própria (má) sorte. Porto Alegre: TCE, 2007. Disponível em: <http://www2.tce.rs.gov.br/portal/page/portal/tcers>. Acesso em: 02 abr. 2011.

RIO GRANDE DO SUL. Tribunal de Contas do Estado. Radiografia da Educação Infantil no RS. Porto Alegre: TCE, 2018. Disponível em: <https:// portal.tce.rs.gov.br/portal/page/portal/tcers/publicacoes/estudos/estudos_pesquisas/radiografia_educacao_infantil_2016_2017>. Acesso em: 02 jun. 2019.

SUSIN, Maria Otilia Kroeff. A Educação Infantil em Porto Alegre: um estudo das creches comunitárias. 2005. 240 f. Dissertação (Mestrado em Educação) - Programa de Pós-Graduação em Educação, Faculdade de Educação, Universidade Federal do Rio Grande do Sul, Porto Alegre, Porto Alegre, 2005. Disponível em: <https://lume.ufrgs.br/handle/10183/6732>. Acesso em: 02 set. 2019.

SUSIN, Maria Otilia Kroeff. A Qualidade da Educação Infantil Comunitária em Porto Alegre: estudo de caso de quatro creches conveniadas. 2009. 306 f. Tese (Doutorado em Educação) - Programa de Pós-Graduação em Educação, Faculdade de Educação, Universidade Federal do Rio Grande do Sul, Porto Alegre, 2009.

VIEIRA, Evaldo. As políticas sociais e os direitos sociais no Brasil. Serviço Social \& Sociedade, São Paulo, p. 67-73, 1998.

VIEIRA, Evaldo. Os Direitos e a Política Social. São Paulo: Editora Cortez, 2004.

WOOD, Ellen Meiksins. Democracia contra o capitalismo: a renovação do materialismo histórico. São Paulo: Boitempo Editorial, 2003.

Vera Maria Vidal Peroni é doutora em Educação e professora convidada do curso de pós-graduação em educação da UFRGS. Participa do grupo nacional de pesquisa sobre a relação entre o público e o privado na educação. É líder do Diretório Grupo de Pesquisa Estado e políticas públicas de Educação Básica. Tem experiência na área de Educação, com ênfase em Política Educacional, atuando principalmente nos seguintes temas: Estado e política educacional, política educacional brasileira, relação público/ privado. Sua pesquisa mais recente trata das Implicações da Relação Público-Privada 
para a Democratização da Educação na América: Argentina, Bolívia, Brasil, Chile, Uruguai e Venezuela.

ORCID: http://orcid.org/0000-0001-6543-8431

E-mail: veraperoni@gmail.com

Maria Otilia Kroeff Susin é doutora em Educação pela Universidade Federal do Rio Grande do Sul. Professora aposentada da Rede Municipal de Ensino de Porto Alegre/RS. Integrante do Grupo de Pesquisa: Relação entre o Público e o Privado na educação (GPRPPE/UFRGS), tem como foco de pesquisa a oferta da Educação Infantil, enquanto direito público a ser assegurado a todas as crianças e suas famílias.

ORCID: http://orcid.org/0000-0002-2361-502X

E-mail: otiliasusin@gmail.com

Monique Montano é professora da Rede Municipal de Porto Alegre na Escola de Ensino Fundamental São Pedro. Atuou no Conselho Municipal de Educação de Porto Alegre. Possui graduação em Pedagogia (FAPA), especialização (UFRGS), Mestrado (UFRGS) e é Doutoranda na Linha de Pesquisa Políticas e Gestão de Processos Educacionais (UFRGS). Compõe o Grupo de Pesquisa: Relação entre o Público e o Privado na educação (GPRPPE/UFRGS). Tem experiência na área de Educação, com ênfase em Gestão, atuando principalmente nos seguintes temas: políticas públicas, democratização, parcerias público privado, educação infantil.

E-mail:moniquerobain@gmail.com

Editora-responsável: Carla Karnoppi Vasques

Este é um artigo de acesso aberto distribuído sob os termos de uma Licença Creative Commons Atribuição 4.0 Internacional. Disponível em: <http:// creativecommons.org/licenses/by/4.0>. 